\title{
UM ESTUDO DOS PROCESSOS VERBAIS NO GÊNERO ARTIGO CIENTÍFICO EM REVISTAS DE SECRETARIADO EXECUTIVO: UMA PERSPECTIVA DA LINGUÍSTICA SISTÊMICO-FUNCIONAL
}

\author{
K. C. A. Portela \\ Pontifícia Universidade Católica de São Paulo e Instituto Federal de Mato Grosso \\ keylaportela@bol.com.br
}

Artigo submetido em março/2013 e aceito em agosto/2013

\section{RESUMO}

Esta pesquisa teve por objetivo investigar os artigos científicos na área do secretariado executivo, por meio da análise das orações com processos verbais, formas verbais mais frequentes e dos padrões de uso, visando auxiliar estudantes, pesquisadores e profissionais de Secretariado Executivo em formação na produção de artigos científicos. Como fundamentação teórica foi utilizada a Linguística Sistêmico-Funcional (LSF), que estuda a língua em uso e em diferentes contextos, desenvolvida por M.A.K Halliday $(1985,1994)$ e revisada por Halliday e Matthiessen (2004), entre outros. Nessa perspectiva, a pesquisa considerou como categoria de análise a metafunção ideacional, tomando por base os processos verbais, ou seja, os processos do dizer. No que se refere aos estudos sobre gêneros científicos, a pesquisa foi fundamentada em Bhatia (1993), Swales (1989, 1990), Swales \& Feak (1999), Motta-Roth (1995,
2006), entre outros. O instrumento computacional WordSmith Tools 5.0 (Scott, 2009) serviu para o mapeamento dos dados da pesquisa a partir, em especial, das ferramentas Wordlist e Concordance, que permitiram encontrar as padrões para análise. Foram estudados 161 artigos, em língua portuguesa, retirados de três revistas online da área de Secretariado executivo, área que ainda não contém publicações no Scielo. Os resultados apontaram que os processos verbais mais recorrentes foram: dizer, determinar, destacar e afirmar nas três revistas e as formas verbais mais encontradas foram: $3^{a}$ pessoa do singular, passiva e infinitivo. Além disso, os padrões de uso mostraram que alguns verbos utilizados não tinham função de processo dizer e, também houve um alto índice de discurso reportado.

PALAVRAS-CHAVE: gênero científico, linguística sistêmico-funcional, processos verbais, WordSmith Tools.

\section{A STUDY OF VERBAL PROCESSES IN SCIENTIFIC ARTICLE GENDER IN JOURNALS OF EXECUTIVE SECRETARIAT: A PERSPECTIVE OF SYSTEMIC FUNCTIONAL LINGUISTICS.}

\begin{abstract}
This research aimed to investigate the scientific articles in the area of executive secretariat, through the of verbal processes, frequent verbal forms and patterns of use, to help students, researchers and professionals in training Executive Secretaries in producing scientific articles. As a theoretical basis, the Systemic Functional Linguistics (SFL) was used, which studies language in use in different contexts - was developed by Halliday (1985, 1994) and reviewed by Halliday and Matthiessen (2004), among others.. From this perspective, the research considers the ideational metafunction, based on verbal processes (i.e. say), as the analysis category. With regard to the scientific study of genres, the research is based on Bhatia (1993), Swales (1989, 1990), Swales \& Feak
\end{abstract}

(1999), Motta-Roth (1995, 2006) and others. The computational instrument WordSmith Tools 5.0 (Scott, 2009) was used to map on data starting by wordlisting and concordance, particular tools that allow patter identification. We studied 161 articles, in English, selected from three online magazines in the Executive Secretariat area, that area does not contain publications in Scielo yet. The results showed that the most frequent verbal processes were: mean, determine, highlight and affirm, and that the most frequent verb forms were: $3 \mathrm{rd}$ person singular, passive and infinitive. Furthermore, the identified patterns showed that some had no verbs function process and, speech high rates were reported.

KEYWORDS: scientific genre, systemic functional linguistics, verbal processes, WordSmith Tools. 


\section{UM ESTUDO DOS PROCESSOS VERBAIS NO GÊNERO ARTIGO CIENTÍFICO EM REVISTAS DE SECRETARIADO EXECUTIVO: UMA PERSPECTIVA DA LINGUÍSTICA SISTÊMICO-FUNCIONAL.}

\section{INTRODUÇÃO}

Pesquisas na área dos estudos linguísticos têm investigado o uso da linguagem em contextos diversos. Nesta pesquisa, o objetivo foi investigar os artigos científicos na área do Secretariado Executivo, por meio da análise das orações com processos verbais, formas verbais mais frequentes e dos padrões de uso, visando auxiliar estudantes, pesquisadores e profissionais de Secretariado Executivo em formação na produção de artigos científicos.

Com este estudo, busca-se tornar explícito o que se torna importante na redação de um artigo científico, fornecendo observações linguísticas relacionadas ao contexto para alcançar os objetivos pretendidos, pois é muito comum a queixa dos professores em relação à produção escrita dos alunos universitários, que, segundo esses professores, não sabem produzir textos científicos. Diante dessa realidade, é necessário um estudo com maior embasamento teórico, que enfoque as estratégias de escrita, observando os recursos linguísticos que os alunos precisam para produzir textos no meio acadêmico.

Há uma série de pesquisas realizadas na área de Secretariado Executivo, como a de Vilas Boas (1999), que discute a metodologia da prática pedagógica para o Secretário Executivo; Lima (2001), que apresenta novas tecnologias comunicacionais na imagem do Secretário; Bruno (2006), que enfoca a importância do Secretário Executivo no processo decisório nas organizações; Pain (2007), que pesquisa estereótipos dos alunos de Secretariado; Marson (2009), que analisa o comportamento organizacional dos Secretários nas empresas do Rio de Janeiro; Almeida (2009), que aborda a re(construção) da identidade dos Secretários na região do ABC; Cavalcante (2010), que reflete sobre a (re)construção da identidade dos secretário por meio das histórias de vida; e Lima (2011) que investiga representação de línguas estrangeira e indígenas pelos Secretários Executivos.

Percebe-se que, embora haja algumas pesquisas realizadas na área de Secretariado Executivo, nenhuma delas contempla estudos sobre os gêneros acadêmicos científicos. Ou seja, não há estudos desenvolvidos na área que auxiliem os secretários executivos na questão da escrita acadêmica e da elaboração de artigos para que se possam encontrar revistas com mais qualidade e que promovam maior inserção em uma base de dados como o Scielo; construindo-se como suporte para leitura, além da produção de novos artigos pelos estudantes, profissionais e pesquisadores desta área.

Este estudo, portanto, se justificou pela necessidade de conhecer melhor as características linguístico-discursivas dos artigos acadêmicos da área do Secretariado Executivo: realizações léxico-gramaticais, modo de produção e uso de projeções de fala. Além disso, na área acadêmica, escrever um artigo científico requer, não somente conhecimento da área de interesse em que o assunto está inserido, mas também requer conhecimentos das estruturas linguísticas que compõe o texto.

A pesquisa baseia-se na fundamentação teórica da Linguística Sistêmico-Funcional (Halliday, 1985 e 1994; Halliday e Mathiessen, 2004), Eggins (2004) e em Thompson (2004), uma teoria sócio-semiótica. Do ponto de vista social, a linguagem é vista como um sistema de significados e que constitui uma relação com a estrutura social. Do ponto de vista semiótico, ela é 
entendida como um entre tantos sistemas de significados e, também como "um sistema de codificação convencionalizado, organizado, como um conjunto de escolhas" (EGGINS, 1994, p.3).

Nesse sentido, adotar uma abordagem sistêmico-funcional para a linguagem envolve investigar não só o uso da língua em diferentes contextos, mas também como a linguagem é estruturada para tal uso. O que diferencia essa abordagem das demais é que ela não procura, apenas, desenvolver uma teoria sobre a linguagem como processo social, mas também uma metodologia analítica que permita uma descrição detalhada e sistemática dos padrões linguísticos (EGGINS, 1994). Desse modo, esta pesquisa prioriza a metafunção ideacional, dando enfoque aos processos verbais que são construídos na consciência humana e realizados pela linguagem.

Para tratar das questões relacionadas sobre os gêneros científicos, foram estudadas as pesquisas desenvolvidas por Bhatia (1993), Swales (1989; 1990), Swales \& Feak (1999) e MottaRoth $(1995 ;$ 2006). Há alguns pesquisadores que realizaram trabalhos com processos verbais e artigos científicos, como Motta-Roth (2010), que estudou os gêneros acadêmicos (resenhas, artigos científicos); Barbara e Macedo (2011), que analisaram processos verbais em artigos científicos nas áreas de Linguística, Economia, Administração; e Morais (2011), que comparou conclusões de artigos científicos nas áreas de Odontologia e Linguística.

Para esta pesquisa, utilizou-se um corpus de 161 artigos retirados de artigos científicos de revistas online ${ }^{1}$, no período de 2001 a 2011, da área de Secretariado Executivo. Recorreremos à Linguística de Corpus, por meio da ferramenta Wordsmith Tools 5.0 (Scott, 2009), para análise da materialidade linguística dos artigos, a base teórico-metodológica da Linguística SistêmicoFuncional (Halliday 1985, 1994) e Halliday e Matthiessen (2004) foi utilizada para verificar os usos dos processos verbais e os estudos acerca de gêneros científicos para compreender como a linguagem é organizada para a circulação do conhecimento e para alcançar tais propósitos sociais.

No decorrer deste artigo, apresentam-se os processos verbais e as formas verbais mais frequentes nos artigos científicos. Logo após, mostram-se os padrões de uso dos processos verbais utilizados pelos os autores que escrevem para as revistas de secretariado executivo analisadas.

\section{LINGUÍSTICA SISTÊMICO-FUNCIONAL: A VISÃO FUNCIONAL DA LINGUAGEM}

A Linguística Sistêmico-Funcional busca descrever detalhadamente a língua em contexto de uso, o que confere especial relevância à correlação entre as propriedades das estruturas gramaticais e as propriedades dos contextos em que ocorrem (Halliday, 2004), explorando a relação entre os significados, as formas léxico-gramaticais, isto é, as realizações linguísticas em instâncias.

Para a Linguística Sistêmico-Funcional, a análise gramatical e do discurso compreendem dois níveis de alcance: contribuir para a compreensão do texto, visando mostrar como e por que o texto transmite significado da maneira como o faz e, também, se relaciona com a avaliação do texto procurando mostrar por que o texto é ou não efetivo para os seus propósitos (Halliday, 1994, p.15).

Para Halliday e Hasan (1989, p.3), a LSF estuda a linguagem a partir de um ponto de vista sociossemiótico, considerando-a como um dos diversos sistemas de criação de significados, os quais fazem parte da cultura de uma sociedade. A língua é um produto do processo social, um

\footnotetext{
${ }^{1}$ Detalhamento das revistas foi realizado na metodologia.
} 
potencial de significado compartilhado; ao mesmo tempo, uma parte e uma interpretação intersubjetiva da experiência (HALLIDAY, 1982). Cada escolha feita no sistema semiótico é significativa, uma vez que adquire seu significado diante das demais possibilidades que havia e que não foram consideradas. É a valorização do nível semântico do conteúdo linguístico, ao lado do nível léxico-gramatical (HALLIDAY e MATTHIESSEN, 2004, p.264).

A Linguística Sistêmico-Funcional ainda difere das teorias gramaticais tradicionais - pois estas últimas descrevem o sistema linguístico como um conjunto de formas e tendem a ser prescritivas - e das que se alinham a conceitos cognitivos, porque se propõe a investigar como e por que fazemos certas escolhas linguísticas colocadas a nosso serviço, bem como procura mostrar qual é a influência do contexto no emprego e interpretação de significados. Para tal, necessita explicar a relação do contexto com o significado e do significado com as palavras. É, ao mesmo tempo, descritiva e interpretativa, pois descreve o sistema linguístico a partir das escolhas de significado que podem ser mais amplamente compreendidas se fatores contextuais forem relevados. Segundo Halliday e Hasan (1989, p.44), a linguagem é estudada tanto para entender seu funcionamento, quanto para compreender como as pessoas dela se utilizam. Segundo Thompson (1996, p.09), uma importante implicação da visão funcional da linguagem é de que o contexto e a linguagem são interdependentes.

Dessa forma, o principal objeto de estudo da gramática funcional é o texto, oral ou escrito, entendido como um produto autêntico de uma interação social que parte de um contexto cultural e social.

Sob a visão de Halliday e Hasan (1989, p.38), todo texto carrega informações sobre o respectivo contexto de uso. Assim sendo, é possível recuperar as características de campo, relações e modo da situação a partir do texto. A LSF descreve a relação entre texto e contexto como um sistema semiótico complexo com vários níveis ou estratos (HALLIDAY e MATTHIESSEN, 2004, p.24).

Halliday e Hasan $(1989$, p.47) falam que a relação entre o texto e o contexto é dialética. Ao mesmo tempo em que a organização sócio-semântica de um contexto impõe certas restrições na produção de um texto que esteja ligado a ela, qualquer texto reflete de modo mais ou menos objetivo o contexto a que pertence. Desse modo, texto e contexto são vistos como aspectos de um mesmo processo, sendo, então, necessário entender os aspectos contextuais que se inserem nos textos a fim de que esses possam ser mais bem examinados e interpretados. Portanto, o texto está sempre inserido em dois contextos: de situação e de cultura.

Para Halliday (1994), o contexto de cultura representa um nível mais abrangente onde se insere o contexto de situação a partir do qual o texto é interpretado. Esses dois contextos abraçam diferentes níveis semióticos abstratos do texto, que são realizados formalmente por meio da linguagem, ao mesmo tempo limitando possíveis interpretações e dando apoio à interpretação intencionada. Desse modo, o contexto de cultura é todo o repertorio de crenças, valores, ideologias da comunidade e está relacionado à noção de propósito social. Assim, pessoas que se utilizam da linguagem para propósitos semelhantes desenvolvem tipos comuns de textos escritos e falados, ou seja, gêneros, que alcançam objetivos comuns.

Para Martin (1984, p.25 apud Eggins, 1994), "o gênero é uma atividade organizada em etapas, orientada para uma finalidade na qual os falantes se envolvem como membros de uma determinada cultura; gênero é como as coisas são feitas, quando a linguagem é usada para realizá-la".

O contexto de situação diz respeito aos padrões, regras de funcionamento de uma interação, que servem para interpretar o contexto social do texto. Halliday (1994) ainda aponta que o contexto de situação é fundamental para nossa atividade de linguagem, uma vez que as 
categorias que o constituem influenciam nossos atos comunicativos e configuram nossos textos. Além disso, é no contexto de situação que o gênero é realizado em linguagem, por meio de escolhas linguísticas que caracterizam o registro, cujas três variáveis são:

(1) Campo: define o evento que está acontecendo (o que ocorre), mediante a identificação dos participantes (quem), as atividades desenvolvidas (processos), e os elementos circunstanciais (quando, onde, etc).

(2) Relações: caracteriza-se pela identificação dos participantes (quem está falando, a natureza dos participantes, seus status e regras); que tipo de relação se estabelece entre os participantes;

(3) Modo: a maneira como o evento se realiza (a organização simbólica do texto e sua função no contexto, incluindo o canal, se falado ou escrito, e também o modo retórico).

Martin e Eggins (1997) propõem uma Teoria do Registro e Gênero que tem um modelo multidimensional de análise de linguagem e de contexto que descreve as semelhanças entre discursos e textos, e mostra como a situação e a cultura aparecem expressas sistematicamente nas escolhas de linguagem por meio da combinação das variáveis do discurso - campo, relações e modo, mapeada nos estágio funcionais, com propósitos socialmente orientados, permitindo tanto a predição textual quanto a dedução contextual.

Para Halliday e Hasan (1989), o gênero torna-se conhecido, entre outros aspectos, pelos significados que atribuímos ou associamos a ele: o gênero, portanto, é social e é concebido como um dos dois planos do contexto; o outro plano do contexto é ocupado pelo registro, o contexto de situação (Martin, 1992, p.495).

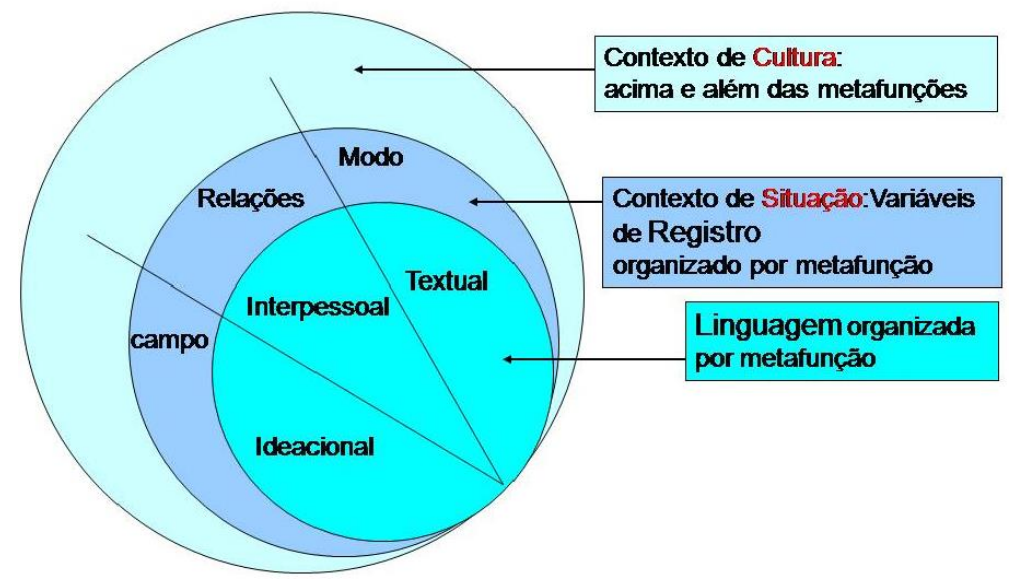

Figura 1: O gênero em relação ao registro e à Língua (Traduzido de: Eggins e Martin,1997, p. 243)

O modelo representado na figura 1 indica como o gênero paira sobre as variáveis de Registro, que por sua vez está em um nível superior ao da realização linguística. Assim, cada variável do contexto de situação está sistematicamente relacionada aos padrões léxicogramaticais existentes em um texto, permitindo sua caracterização a partir dessas escolhas.

A teoria de gênero e registro proposta por Eggins e Martin (1997) sugere que tenhamos o contexto de cultura como ponto de partida para análise. Para tanto, algumas questões devem ser consideradas, partindo de um alargamento das teorias de gênero e registro. Essas teorias têm como foco a variação funcional, ou seja, a explicação das diferenças presentes nos textos em relação às motivações contextuais que levam a essas diferenças, permitindo a predição textual e a dedução contextual. Em outras palavras, para explicarmos essas diferenças devemos analisar a variação de elementos linguísticos no discurso, identificando e quantificando padrões gramaticais 
e semânticos em um dado texto e relacionando esses elementos às variáveis de valor social e cultural presentes no texto. Ainda para os autores, o gênero engloba o registro juntamente com suas variáveis do contexto e as respectivas realizações semântico-funcionais, ou seja, as metafunções.

Para Halliday (1985) as três variáveis do registro são realizadas respectivamente nas metafunções: interpessoal, textual e ideacional.

A metafunção interpessoal representa a interação e os papéis assumidos pelos participantes mediante o sistema de Modo. A metafunção textual está ligada ao fluxo de informações e organiza a textualização por meio do sistema temático. A metafunção ideacional representa/constrói os significados de nossa experiência, tanto do mundo exterior (social) quanto do mundo interior (psicológico), por meio do sistema de transitividade (HALLIDAY, 1994, p.190-191).

A metafunção ideacional, priorizada neste trabalho, trata do uso da língua como representação, servindo para manifestações sobre o mundo, destacando como ele é percebido, sentido, experienciado e representado. Os seus componentes são o experiencial (conteúdo e ideias) e o lógico (relação entre ideias). O falante/escritor fala ou escreve sobre os fatos e organização do mundo exterior (acontecimentos, coisas, qualidades) e do seu mundo interior (pensamentos, crenças, sentimentos) (HALLIDAY, 1994, p.106).

Na metafunção ideacional, o sistema chamado de "transitividade" é responsável por fornecer a estrutura linguística que interpreta a experiência humana sobre o que está acontecendo no mundo. É um sistema gramatical que explica esse mundo de experiências por meio de tipos de processos (HALLIDAY, 1994, p.106).

A transitividade é composta por três elementos principais: os participantes (aqueles que realizam a ação ou são afetados), os processos (ações ou estados propriamente ditos - grupos verbais) e as circunstâncias (cuja função é a de acrescentar informações às ações representadas pelos processos). Halliday (1994) divide os processos em seis tipos: três principais (material, mental, relacional) e três intermediários (comportamental, verbal, existencial). Cada processo possui sua especificidade, sendo: 1) processos materiais: relacionam-se a ações físicas, concretas; 2) processos mentais: relacionam-se a reações mentais; 3) processos relacionais: referem-se à ordem do "ser"; 4) processos comportamentais: estão ligados a comportamentos fisiológicos e psicológicos; 5) processos verbais: relacionados ao "dizer" e comunicar; e 6) processos existenciais: referem-se ao que existe ou acontece.

$\mathrm{Na}$ figura 2, visualizam-se os seis tipos de processos organizadas em torno de diferentes campos semânticos da experiência humana: Material, Existencial, Relacional, Verbal e Mental. (HALLIDAY E MATHIESSEN, 2004, p.167- 280)

A organização dos diferentes tipos de processo em uma figura circular visa demonstrar que há certa continuidade nos significados das ações e experiência humanas e no significado dos processos. Alguns processos são classificados como principais, como Material, Mental e Relacional, e os considerados de fronteira, como Comportamental, Verbal e Existencial.

Os processos verbais situam-se em um contínuo entre os relacionais e os mentais, compartilhando características de ambos e, assim, constituindo um tipo em particular, além de serem relações simbólicas construídas na consciência humana e realizadas por meio da linguagem (HALLIDAY \& MATTHIESSEN, 2004, p. 171). Organizam-se a partir de quatro possíveis participantes: dizente - quem emite a mensagem, mas nem sempre é humano; receptor - para quem a mensagem é dirigida, tipicamente humano, no entanto, pode ser coletivo ou instituição; alvo - a que/quem se destina e a verbiagem - o que é dito, representando uma classe de coisas ditas (BARBARA e MACEDO, 2011, p. 221). 


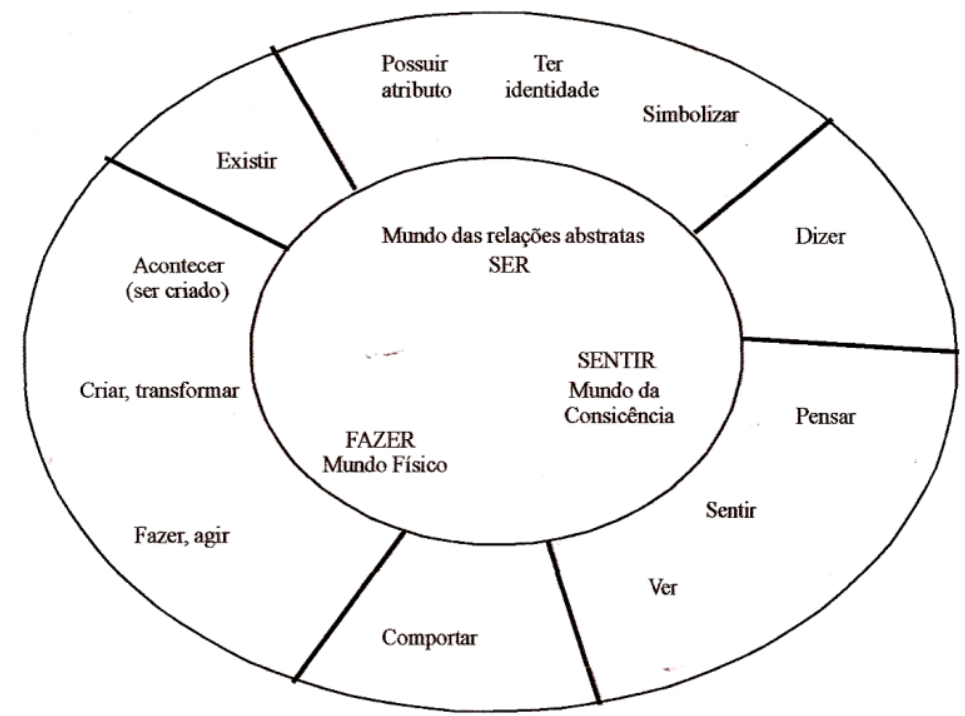

Figura 2: Tipos de Processos (traduzida de Halliday e Mathiessen, 2004, p.172)

Halliday e Matthiessen (2004) também falam que os processos verbais desempenham papel importante no discurso porque servem para criar passagens dialógicas em narrativas escritas e situações de diálogos em narrativas orais.

Para Cabral e Barbara (2012) as orações com processos verbais contribuem, por sua característica de fala, para a existência de passagens dialógicas; permitem ao jornalista atribuir informações a fontes exteriores (oficiais, experts, testemunhas oculares, etc.) e desempenham um relevante papel nos trabalhos acadêmicos, citando e relatando a fala de pesquisadores.

\section{O GÊNERO ARTIGO CIENTÍFICO}

Para entender como se dá a comunicação em uma dada esfera social, é preciso investigar os gêneros usados na interação e propósitos dos participantes desta esfera, considerando aspectos linguísticos e discursivos.

Swales (1990) enfatiza a relevância do propósito comunicativo do texto ao analisar textos produzidos para fins acadêmicos e profissionais. O autor ainda ressalta que é o propósito comunicativo que molda o gênero, determinando sua estrutura interna e impondo limites quanto às possibilidades de ocorrências linguísticas e retóricas. Ele também apresenta três conceitoschave para definir o que é gênero: um evento comunicativo, um propósito comunicativo, e uma comunidade discursiva. O evento comunicativo é qualquer evento "onde a linguagem desempenha um papel significativo e indispensável" (SWALES, 1990, p.45). Chama a atenção, ainda, para o propósito comunicativo compartilhado por um determinado grupo denominado comunidade discursiva, enfatizando o aspecto de grupo ou de comunidade inerente ao conceito e à configuração de um gênero. Para esse autor, o texto deve ser visto em seu contexto e não pode ser completamente entendido e interpretado somente por meio da análise de elementos linguísticos. A partir daí, o autor se volta para o conceito de gênero.

Swales (1990, p.58) constrói sua definição de gênero da seguinte forma:

Gênero compreende uma classe de eventos comunicativos, cujos membros compartilham algum conjunto de propósitos comunicativos. Estes propósitos são reconhecidos pelos membros especialistas da comunidade discursiva, e não por constituírem a razão de ser do gênero. Essa lógica molda a estrutura esquemática do 
discurso e influencia restrições e escolha de conteúdo e estilo. O propósito comunicativo é um critério privilegiado no intuito de conceber o gênero de forma restrita e centrado na ação retórica. Além disso, exemplares de um gênero exibem vários padrões de similaridade em termos de estrutura, estilo, conteúdo e público-alvo. Se todas as probabilidades esperadas são realizadas, o exemplar será visto como prototípico da comunidade discursiva. O gênero herdado e produzido pelas comunidades discursivas e importado por outros constitui uma comunicação etnográfica valiosa, porém geralmente necessitam de uma maior validação.

A definição apresentada aponta claramente para o principal traço definidor de gênero sob a perspectiva do autor nessa obra, que é o propósito comunicativo compartilhado pelos membros da comunidade na qual o gênero é usado.

Bhatia (1993) corrobora a posição de Swales quanto ao critério de maior relevância para a definição de gêneros (e a identificação de possíveis subgêneros): o propósito comunicativo. Qualquer mudança significativa no propósito comunicativo provavelmente resultará em um gênero diferente, ao passo que modificações menores nos ajudam a distinguir os subgêneros.

O gênero, uma vez estabelecido, torna-se um ambiente estruturado para a escrita e para a leitura, que, por sua vez, exerce influência sobre os outros aspectos do trabalho profissional. Exemplo disso é o gênero artigo científico que é usado por pesquisadores para divulgação de pesquisas.

O artigo científico se insere na esfera discursiva dos gêneros acadêmicos, é considerado como uma maneira de participar, agir e construir o conhecimento científico sócio-retórico, além de estar no domínio discursivo da ciência, ele mostra as ações sociais de produção do conhecimento. Esse tipo de gênero resulta em um relato sobre pesquisas desenvolvidas por cientistas e tem o objetivo de divulgar os resultados obtidos no meio científico, trazendo novas propostas, teorias e exercendo a função de disseminador da pesquisa científica, utilizando-se de aspectos linguísticos específicos com uma linguagem objetiva, usos de termos técnicos e algumas vezes fazendo o ocultamento do produtor do texto.

Swales (1990) afirma que o artigo científico é um gênero da comunidade acadêmica e disciplinar, além de ser considerado um dos principais veículos de socialização do conhecimento e de exercer a função de inserir novos pesquisadores nas comunidades científicas também está relacionado com descobertas científicas. Esse autor (1990, p.93) ainda conceitua o artigo científico (research article) como um texto escrito (embora possa conter elementos da linguagem não verbal), com o uso limitado de palavras que se reportam a algumas pesquisas por um ou mais autores.

Motta-Roth (1995) diz que os gêneros acadêmicos são os mais utilizados por pesquisadores na leitura e publicação científicas e estão em capítulos de livros e artigos de revistas acadêmicas. Nesse contexto, podemos considerar o artigo científico um dos gêneros mais utilizados no ambiente científico como forma de acesso e de produção de conhecimento científico.

Motta-Roth (2010, p.65) ainda traz o gênero artigo científico como sendo uma via de comunicação entre pesquisadores, profissionais, professores e alunos de graduação e pósgraduação. Portanto, é necessário que os autores saibam articular a linguagem (formato e vocabulário técnico) para imprimir as convenções do registro da área em que atuam e escrever pesquisas seguindo os hábitos da área, apresentar o problema, apresentar dados, avaliar os resultados, argumentar e tirar conclusões, fazendo com que a informação circule e tenha impacto na área do conhecimento. 
Para Marcantonio et al. (1993), “os artigos científicos são resultados de estudos completos de um dado objeto de pesquisa. Não chegam a constituir-se em matéria para dissertações, teses ou livros. Apresentam as pesquisas realizadas e são publicados em revistas ou periódicos especializados".

Na visão de Berkenkotter e Huckin (1995, p.275 apud Kanoksilapatham, 2005), o "artigo científico é fruto da atividade de pesquisa da comunidade de onde foi gerado, e que apresenta como características a alusão a outras pesquisas ou autores que compartilham ou não do mesmo assunto tratado, uma apresentação de objetivos posteriores à identificação de um problema apontado, a citação de outras pesquisas que possam corroborar na apresentação e a generalização dos resultados obtidos".

Nesse sentido, o artigo pode ser considerado como meio responsável pela divulgação de um estudo, reunindo etapas que se estendem desde a contextualização de uma pesquisa até a conclusão do estudo realizado.

\section{METODOLOGIA}

Tendo apresentado os aportes teóricos fundamentais que embasaram esta pesquisa, como também, a abordagem realizada, nesta seção, apresento os procedimentos metodológicos que foram utilizados para a sua efetivação.

\section{O corpus}

O corpus desta pesquisa foi composto de 161 artigos científicos de língua portuguesa, produzidos na área de Secretariado Executivo publicados nas revistas online, no período de 2001 a 2011, intituladas: Revista Expectativa - Qualis B5, Revista Gestão e Secretariado - Qualis B3 e Secretariado em Revista, Qualis $C$, as únicas revistas científicas da área no Brasil.

Os artigos foram salvos em Word e convertidos em formato txt, para a utilização do programa Wordsmith Tools (Scott, 2009), pois este software apenas faz a leitura em textos nesse formato. Cada artigo foi salvo em um arquivo, eliminando figuras, gráficos, quadros, palavraschave, abstracts e referências bibliográficas, por não ser objeto de estudo, pois a relevância deste estudo está voltada para a materialidade linguística da tessitura dos textos. De acordo com Halliday \& Mathiessen (2004, p.35), o uso da tecnologia permite que uma maior quantidade de dados seja analisada, mostrando diferentes facetas da língua e seus usos em diferentes registros.

\section{Procedimentos de análise}

Para a análise quantitativa dos dados foi utilizada o programa computacional Wordsmith Tools (Scott, 2009), que permitiu gerar rapidamente uma lista de palavras (Wordlist) de um corpus selecionado, bem como elaborar listas de concordâncias (Concordance) de palavras dos textos. Este instrumento computacional foi um grande aliado para análise de grandes quantidades de textos em prazos relativamente curtos conforme utilizado na abordagem metodológica da Linguística de Corpus (LC) que é definida como uma área da Linguística que "se ocupa da coleta e exploração de corpora, ou conjunto de dados linguísticos textuais, em formato legível por computador, que foram coletados criteriosamente com o propósito de servirem para a pesquisa de uma língua ou variedade linguística" (BERBER-SARDINHA, 2004, p.3). 
Para alcançar os objetivos, o WST foi utilizado para quantificar os usos dos processos verbais por meio da ferramenta Wordlist e, por meio do Concordance, para identificar as estruturas de uso dos processos verbais mais presentes na elaboração dos artigos científicos dos corpora a serem estudados.

Após a análise quantitativa por meio das ferramentas computacionais, a materialidade linguística do corpus foi analisada qualitativamente, utilizando a teoria da Linguística SistêmicoFuncional (LSF), com foco na metafunção ideacional analisando os processos verbais.

\section{RESULTADOS E DISCUSSÕES}

A Tabela 1 mostra os dados quantitativos do corpus a ser analisado que foram retirados por meio do software WordSmith Tools 5.0 (Scott, 2009) utilizando-se da ferramenta wordlist para encontrar os processos verbais mais empregados nos artigos científicos.

Tabela 1 - Caracterização geral do corpus

\begin{tabular}{l|c|c|c|c}
\hline \multicolumn{1}{c|}{ REVISTA } & $\begin{array}{c}\text { REVISTA } \\
\text { EXPECTATIVA }\end{array}$ & $\begin{array}{c}\text { REVISTA GESTÃO } \\
\text { E SECRETARIADO }\end{array}$ & $\begin{array}{c}\text { SECRETARIADO } \\
\text { EM REVISTA }\end{array}$ & TOTAL \\
\hline $\begin{array}{l}\text { Número de } \\
\text { palavras } \\
\text { nos textos }\end{array}$ & $5.240,426$ & 936,377 & $2.511,527$ & $8.688,330$ \\
\hline $\begin{array}{l}\text { Número de } \\
\text { palavras } \\
\text { diferentes }\end{array}$ & 344,880 & 176,430 & 293,450 & 814,760 \\
\hline $\begin{array}{l}\text { Número de } \\
\text { bits }\end{array}$ & $191.817,728$ & $4.468,992$ & $16,588,231$ & $212.874,951$ \\
\hline $\begin{array}{l}\text { Número de } \\
\text { orações }\end{array}$ & 105,234 & 71,523 & 94,065 & 270,822 \\
\hline $\begin{array}{l}\text { Número de } \\
\text { artigos }\end{array}$ & 92 & 23 & 46 & 161 \\
\hline
\end{tabular}

Em seguida, a ferramenta de análise Wordlist foi utilizada para elaborar uma lista de verbos de 45 processos verbais mais recorrentes no corpus, sendo tomado como ponto de corte o décimo verbo mais frequente. São eles: dizer, determinar, estabelecer, destacar, afirmar, definir, mostrar, falar, demonstrar e responder, que foram pesquisados em todos os tempos e formas que se apresentaram no corpus. Além disso, também foi possível realizar a distribuição no que tange à incidência dos processos verbais nos artigos científicos, exibindo um número de ocorrências em porcentagem.

$\mathrm{Na}$ Tabela 2, é possível verificar que o processo verbal mais recorrente foi o processo DIZER com 516 ocorrências, ou seja, 7,21\% de recorrência no corpus.

Para chegar a uma análise qualitativa dos dados, utilizou-se da ferramenta Concordance do software Wordsmith Tools 5.0 (Scott, 2009) e com a qual foi possível verificar as formas verbais e as categorias de usos dos processos nas revistas científicas. Analisou, apenas, os primeiros quatro processos verbais mais recorrentes no corpus: dizer, determinar, destacar e afirmar. 
Tabela 2 - Verbos mais frequentes

\begin{tabular}{c|l|c|c}
\hline № & PALAVRA & FREQUÊNCIA & $\%$ \\
\hline $\mathbf{1}$ & dizer & 516 & 7,21 \\
\hline $\mathbf{2}$ & determinar & 454 & 6,34 \\
\hline $\mathbf{3}$ & destacar & 338 & 4,72 \\
\hline $\mathbf{4}$ & afirmar & 332 & 4,64 \\
\hline $\mathbf{5}$ & estabelecer & 323 & 4,51 \\
\hline $\mathbf{6}$ & Definir & 305 & 4,26 \\
\hline $\mathbf{7}$ & Mostrar & 304 & 4,25 \\
\hline $\mathbf{8}$ & Falar & 275 & 3,84 \\
\hline $\mathbf{9}$ & Demonstrar & 263 & 3,67 \\
\hline $\mathbf{1 0}$ & responder & $\mathbf{2 2 4}$ & 3,13 \\
\hline
\end{tabular}

Primeiramente, verificou-se o processo DIZER, conforme tabela 3, tendo em vista que ele foi o processo mais recorrente na análise estatística deste corpus e suas formas verbais, as mais usadas pelos pesquisadores que escrevem nestas revistas.

Tabela 3 - Frequência das formas verbais de DIZER

\begin{tabular}{l|c|c|c|c}
\hline $\begin{array}{l}\text { FORMA } \\
\text { VERBAL/No } \\
\text { OCORRÊNCIAS }\end{array}$ & $\begin{array}{c}\text { REVISTA } \\
\text { EXPECTATIVA }\end{array}$ & $\begin{array}{l}\text { REVISTA GESTÃO } \\
\text { E SECRETARIADO }\end{array}$ & $\begin{array}{c}\text { SECRETARIADO } \\
\text { EM REVISTA }\end{array}$ & TOTAL \\
\hline DIZ & 119 & 32 & 68 & 219 \\
\hline DIZER & 82 & 26 & 68 & 176 \\
\hline DIZEM & 23 & 3 & 17 & 43 \\
\hline DIZEMOS & 3 & 1 & 1 & 5 \\
\hline DISSE & 2 & 3 & 5 & 10 \\
\hline DIZIA & 1 & 1 & 7 & 9 \\
\hline DIZENDO & 0 & 3 & 11 & 14 \\
\hline DISSERAM & 0 & 0 & 3 & 3 \\
\hline
\end{tabular}

Nota-se que a maior quantidade de ocorrência foi na forma DIZ, 3ำ pessoa do singular, nas três revistas. A formal verbal DIZENDO não teve ocorrência na Revista Expectativa, e DISSERAM não ocorreu nas revistas Expectativa nem em Gestão e Secretariado.

Após a verificação do DIZER, analisou-se, na tabela 4, o segundo processo mais recorrente, DETERMINAR.

Analisando a Tabela 4 foi possível verificar que a forma verbal mais recorrente nas três revistas foi forma passiva, DETERMINADA.

A forma passiva é uma maneira de o interlocutor, ao mesmo tempo, se esconder e aparecer no discurso, dependendo do grau de sua aceitação dentro da academia.

Analisando a Tabela 4 foi possível verificar que a forma verbal mais recorrente nas três revistas foi forma passiva, DETERMINADA.

A forma passiva é uma maneira de o interlocutor, ao mesmo tempo, se esconder e aparecer no discurso, dependendo do grau de sua aceitação dentro da academia. 
Tabela 4 - Frequência das formas verbais de DETERMINAR

\begin{tabular}{l|c|c|c|c}
\hline $\begin{array}{l}\text { FORMA VERBAL/No } \\
\text { DE OCORRÊNCIAS }\end{array}$ & $\begin{array}{c}\text { REVISTA } \\
\text { EXPECTATIVA }\end{array}$ & $\begin{array}{c}\text { REVISTA GESTÃO } \\
\text { E SECRETARIADO }\end{array}$ & $\begin{array}{c}\text { SECRETARIADO } \\
\text { EM REVISTA }\end{array}$ & TOTAL \\
\hline DETERMINA & 15 & 9 & 0 & 24 \\
\hline DETERMINADA & 56 & 18 & 36 & 110 \\
\hline DETERMINAM & 7 & 5 & 5 & 17 \\
\hline DETERMINAR & 14 & 0 & 9 & 23 \\
\hline DETERMINOU & 1 & 1 & 2 & 4 \\
\hline DETERMINANDO & 1 & 2 & 2 & 5 \\
\hline DETERMINAVA & 1 & 1 & 2 & 4 \\
\hline DETERMINARÁ & 4 & 0 & 1 & 5 \\
\hline
\end{tabular}

Corroborando o exposto acima, Swales \& Feak (1999) apontam que o uso de passiva é um recurso frequentemente utilizado no gênero científico, pois evita a identificação do agente humano nas atividades realizadas na pesquisa e também na forma de interação com o leitor, já que $o$ autor não aparece nos textos de forma explícita.

Segundo Taschetto (2002, p.109), dessa maneira "o sujeito atenua a sua presença agindo de acordo com a norma que rege o discurso acadêmico, isto é, privilegiando uma linguagem objetiva de afastamento ou isenção do objeto em estudo".

Após a verificação do DETERMINAR, analisou-se, na tabela 5, o terceiro processo mais recorrente, DESTACAR.

Tabela 5 - Frequência das formas verbais de DESTACAR

\begin{tabular}{l|c|c|c|c}
\hline $\begin{array}{l}\text { FORMA VERBAL/NN DE } \\
\text { OCORRÊNCIAS }\end{array}$ & $\begin{array}{c}\text { REVISTA } \\
\text { EXPECTATIVA }\end{array}$ & $\begin{array}{c}\text { REVISTA GESTÃO } \\
\text { E SECRETARIADO }\end{array}$ & $\begin{array}{c}\text { SECRETARIADO } \\
\text { EM REVISTA }\end{array}$ & TOTAL \\
\hline DESTACAR & 36 & 4 & 18 & 58 \\
\hline DESTACA & 71 & 7 & 29 & 107 \\
\hline DESTACADO & 15 & 2 & 6 & 23 \\
\hline DESTACARAM & 9 & 1 & 4 & 13 \\
\hline DESTACOU & 1 & 1 & 7 & 9 \\
\hline DESTACANDO & 20 & 3 & 8 & 31 \\
\hline DESTACAM & 21 & 3 & 19 & 43 \\
\hline
\end{tabular}

Nessa tabela, percebe-se que a ocorrência maior na forma verbal foi na $3^{3}$ pessoa do singular nas três revistas. Essa alta ocorrência da $3^{3}$ a pessoa do singular mostra o caráter impessoal do artigo científico.

Após a verificação do DESTACAR, analisou-se, na tabela 6 , o quarto processo mais recorrente, AFIRMAR.

$\mathrm{Na}$ tabela 6, pode-se notar que a forma verbal mais recorrente foi o infinito AFIRMAR em todas as revistas. $O$ uso de infinitivo relaciona-se prioritariamente ao alto uso de modalidade (BARBARA e MACEDO, 2011). 
Tabela 6 - Frequência das formas verbais de AFIRMAR

\begin{tabular}{l|c|c|c|c}
\hline $\begin{array}{l}\text { FORMA VERBAL/No DE } \\
\text { OCORRÊNCIAS }\end{array}$ & $\begin{array}{c}\text { REVISTA } \\
\text { EXPECTATIVA }\end{array}$ & $\begin{array}{c}\text { REVISTA GESTÃO } \\
\text { E SECRETARIADO }\end{array}$ & $\begin{array}{c}\text { SECRETARIADO } \\
\text { EM REVISTA }\end{array}$ & TOTAL \\
\hline AFIRMAR & 45 & 24 & 31 & 100 \\
\hline \multicolumn{1}{c|}{ AFIRMAM } & 15 & 9 & 12 & 36 \\
\hline AFIRMANDO & 7 & 3 & 7 & 17 \\
\hline AFIRMOU & 6 & 3 & 3 & 12 \\
\hline AFIRMA & 77 & 23 & 52 & 152 \\
\hline AFIRMAREM & 0 & 1 & 1 & 2 \\
\hline AFIRMARAM & 9 & 0 & 3 & 12 \\
\hline
\end{tabular}

O uso de orações verbais está relacionado ao gênero do discurso em questão, um processo muito frequente no contexto dos artigos científicos, pois carregam a função obrigatória de mencionar outros autores e estudos, na maioria das vezes, consagrados na área da publicação (CABRAL e BARBARA, 2012). Assim, um artigo científico vai reportar sempre a outras vozes com verbo discendi.

Após analisar as formas verbais mais recorrentes nas revistas, utilizou-se novamente da ferramenta Concondance para encontrar alguns padrões de uso, ou seja, agrupamento lexicais, utilizou-se dos instrumentos clusters que mostraram uma lista de sequências fixas de palavras recorrentes na concordância. Utilizando essas ferramentas, encontraram-se alguns padrões comuns nos verbos mais recorrentes das três revistas, entre os quais destacam-se os verbos DIZER, AFIRMAR e DESTACAR.

As orações com processos verbais contribuem, por sua característica de fala, para a existência de passagens dialógicas desempenhando um relevante papel nos artigos científicos.

Vejamos na tabela 8 os padrões de usos mais recorrentes nas três revistas com o processo DIZER.

Tabela 7 - Padrões de uso com DIZER

\begin{tabular}{l|c|c|c}
\hline PADRÕES DE USO & $\begin{array}{c}\text { REVISTA } \\
\text { EXPECTATIVA }\end{array}$ & $\begin{array}{c}\text { REVISTA GESTÃO } \\
\text { E SECRETARIADO }\end{array}$ & $\begin{array}{c}\text { SECRETARIADO } \\
\text { EM REVISTA }\end{array}$ \\
\hline DIZ RESPEITO A & 57 & 13 & 38 \\
\hline PODE-SE DIZER & 23 & 9 & 12 \\
\hline PODEMOS DIZER QUE & 34 & 0 & 19 \\
\hline DIZ QUE & 27 & 16 & 21 \\
\hline QUER DIZER & 21 & 8 & 14 \\
\hline
\end{tabular}

Nos padrões encontrados acima, alguns verbos não exercem função de processo verbal nas estruturas usadas nos artigos científicos. A categoria "diz respeito à", tem a ideia de "SIGNIFICAR, RELACIONAR, RESULTAR e REFERIR". Vejamos alguns exemplos:

1. O controle diz respeito à definição de padrões para o monitoramento e avaliação do desempenho. (SV10.09)

2. ...os objetivos que tem em mente numa determinada situação comunicativa; enquanto a aceitabilidade diz respeito à atitude do interlocutor, ou seja, a de recebedor o que lhe é apresentado como texto. (RE10.10) 
3. Outro ponto a ser discutido diz respeito à língua portuguesa, pois apesar de as notas médias atribuídas... (RGS08.11)

Nota-se que o padrão de uso mais utilizado foi diz respeito a nas três revistas estudadas. No entanto, este padrão de uso não é considerado como processo verbal conforme explicitado acima.

Na tabela 8 , buscou-se encontrar os padrões com processo AFIRMAR.

Tabela 8 - Padrões de uso com AFIRMAR

\begin{tabular}{l|c|c|c}
\hline PADRÕES DE USO & $\begin{array}{c}\text { REVISTA } \\
\text { EXPECTATIVA }\end{array}$ & $\begin{array}{c}\text { REVISTA GESTÃO } \\
\text { E SECRETARIADO }\end{array}$ & $\begin{array}{c}\text { SECRETARIADO } \\
\text { EM REVISTA }\end{array}$ \\
\hline AFIRMA QUE & 31 & 14 & 23 \\
\hline PODE-SE AFIRMAR & 28 & 11 & 14 \\
\hline É POSSÍVEL AFIRMAR & 9 & 3 & 5 \\
\hline PODEMOS AFIRMAR & 12 & 4 & 9 \\
\hline AFIRMAM QUE OS & 15 & 4 & 8 \\
\hline
\end{tabular}

Tabela 9 - Padrões de uso com DESTACAR

\begin{tabular}{l|c|c|c}
\hline PADRÕES DE USO & $\begin{array}{c}\text { REVISTA } \\
\text { EXPECTATIVA }\end{array}$ & $\begin{array}{c}\text { REVISTA GESTÃO } \\
\text { E SECRETARIADO }\end{array}$ & $\begin{array}{c}\text { SECRETARIADO } \\
\text { EM REVISTA }\end{array}$ \\
\hline PODE-SE DESTACAR & 13 & 2 & 9 \\
\hline CABE DESTACAR QUE & 21 & 2 & 9 \\
\hline DESTACA-SE QUE & 38 & 4 & 14 \\
\hline DESTACAM QUE & 16 & 3 & 9 \\
\hline DESTACA-SE AINDA & 23 & 4 & 11 \\
\hline
\end{tabular}

Após análise das tabelas 8 e 9, processos com AFIRMAR e DESTACAR, notou-se uma grande semelhança na ocorrência do padrão de uso com a palavra QUE. Essa palavra é utilizada para indicar discursos reportados. Nas duas tabelas acima, a alta ocorrência foi utilizada para reportar discursos de outros estudiosos reverenciados na área científica, portanto, apropriado no uso de citações ou mesmo de discurso reportado.

Utiliza-se discurso reportado como estratégia para introduzir argumentos e também desenvolvê-los. Independentemente do verbo, o discurso reportado (verbo + que) é uma estratégia usada com frequência pelos autores dos artigos científicos para desenvolver seus argumentos, como podemos observar nos exemplos de 4 a 7.

4. Souza (2006) afirma que é imprescindível profissionalizar a gestão, para evitar a sobreposição dos interesses pessoais. (GS10.5)

5. Os coordenadores do setor de treinamentos afirmam que os treinamentos desenvolvidos na empresa, tanto interno quanto externo são evidenciados.... (SR08.09)

6. Os estudos de Bondarik (2006) e Moreira (2202) destacam que muitos já perceberam que não é mais suficiente apenas oferecer produtos... (RE09.10) 
Guimarães (2205) também destaca que o método tradicional de processamento de informação está sendo substituído pelo automatizado. (SR02.08)

7. O mesmo autor destaque que no século XVI vários casos de fusões. (SR.05.09)

O discurso reportado (verbo + que), também, é uma estratégia usada com frequência pelos autores dos artigos científicos principalmente, para ocultar a subjetividade, o que de certa forma preserva o estereótipo de objetividade do discurso da ciência. Vejamos outros exemplos retirados das revistas estudadas:

8. Cabe destacar que o objetivo maior na opção pelo estágio curricular, deve-se a necessidade de.... (RE02.10)

9. Ainda neste contexto, cabe destacar que a administração das universidades é fundamental para o seu correto desenvolvimento... (RG02.10)

10. Destaca-se que não houve o propósito de investigar somente secretários com formação na área... (SR04.10)

No discurso da ciência, os autores argumentam a favor de suas proposições, baseados em evidências apoiadas em resultados de pesquisas ou em elaborações teóricas. Sendo assim, utilizam o discurso reportado para fazer referências a trabalhos de outros estudiosos da área e, a partir da aceitação ou não das proposições apresentadas, fundamentar o seu posicionamento (BARBARA E MACEDO, 2011).

\section{CONSIDERAÇÕES FINAIS}

As análises aqui empreendidas e sustentadas, sobretudo sob a ótica da Linguística Sistêmico Funcional, permitiram atingir o objetivo desta pesquisa que foi investigar os artigos científicos online na área do secretariado executivo, por meio da análise das orações com processos verbais e dos principais recursos linguísticos. Os artigos científicos são de publicações de revistas na área de secretariado de 2001 a 2011.

Buscando atingir o primeiro objetivo da pesquisa, que foi analisar a frequência dos processos verbais nos artigos científicos, verificou-se que os processos verbais mais recorrentes foi o processo DIZER, verbo prototípico de declaração e fala. Em relação ao, segundo objetivo, que foi verificar as formas verbais mais utilizados pelos pesquisadores que escrevem nas três revistas científicas, encontrou-se a maior recorrência o uso de 3 a pessoa do singular, a passiva e o infinitivo. O terceiro objetivo foi analisar as categorias de padrões de usos dos processos verbais. Nesse sentido, percebeu-se que alguns processos não desempenham apenas a função verbal e, sim, de outros processos dentro da metafunção ideacional com significados como de mostrar, relacionar, resultar e significar, além do uso do discurso reportado e de discursos modais.

Assim, após a análise, pôde-se inferir que os processos verbais utilizados pelos autores que escrevem artigos nessas revistas, empregam verbos que não possuem a real função de dizer.

Do ponto de vista da Linguística Sistêmico-Funcional, o estudo de uma língua deve considerar a forma como essa está sendo efetivamente usada pelos falantes/escritores, em cada um dos contextos de produção do texto. (HALLIDAY E MATTHIESSEN, 2004). 
Este estudo foi importante para área secretarial, pois foi possível identificar quais os verbos mais utilizados e seus usos, podendo notar que nem sempre o autor utiliza o verbo dizer com a função de discendi, pois é uma mudança que estamos percebendo na língua através dos artigos acadêmicos por ora analisados. Além disso, esta pesquisa também pode ser útil aos estudos associados à linguagem, especificamente, sobre o estudo da linguagem presente nos artigos científicos, além de auxiliar os usuários da língua portuguesa na percepção de que todas as escolhas no nível gramatical repercutem na construção de sentido de tudo o que dizemos ou escrevemos, ou seja, em todos os gêneros que utilizamos em nossas interações cotidianas.

\section{REFERÊNCIAS BIBLIOGRÁFICAS}

1. ALMEIDA, R. A construção da identidade do profissional de secretário na região do Grande ABC - Dissertação de Mestrado - Medodista - Departamento de Administração, 2009.

2. BARBARA, L; MACEDO, M. M. Processos verbais em artigos científicos: padrões de realização da mensagem. IN: BARBARA, L; MOYANO, E. Textos e Linguagem acadêmica. Mercado de Letras, 2011.

3. BHATIA, V. K. Analysing genre: language use in professional settings. Longman, 1993.

4. BERBER-SARDINHA, T. Linguística de corpus. São Paulo: Manole, 2004.

5. BRUNO, I. M. O Poder de Influência do Profissional de Secretariado no Processo Decisório das Organizações Dissertação de Mestrado - PUCSP - Departamento de Administração, 2006.

6. CABRAL, S. R. S.; BARBARA, L. Processos verbais no discurso jornalístico: frequência e organização da mensagem. Delta. 2012.

7. CAVALCANTE, F. L. A (Re) Construção da Identidade Profissional de Secretária: Um Estudo de Estórias de Vida. Dissertação de Mestrado - PUCRJ - Departamento de Letras, 2010.

8. EGGINS, S. An introduction to systemic functional linguistics. London: Pinter Publishers, 1994.

9. HALLIDAY, M.A.K. An introduction to functional grammar. London: Edward Arnold, 1994.

10. HALLIDAY, M.A.K. \& HASAN, R. Cohesion in English. London: Longman, 1976.

11. Language, context, and text: aspect of language in a social-semiotic perspective. Second Edition. Deakin University Press/ Oxford University Press, 1989.

12. LIMA, L. C. Línguas em Contato, Preconceitos e Ensino, um Estudo de Caso: Representação de Línguas Estrangeiras e Indígenas na Formação do Profissional de Secretariado Executivo em Roraima. Dissertação de Mestrado - UFRJ - Departamento de Letras, 2011.

13. LIMA, S. F. De que Maneira as Novas Tecnologias Comunicacionais vêm Mudando a Imagem da Secretária Executiva nas Organizações. Dissertação de Mestrado - LAEL - PUCSP, 2001.

14. LIMA-LOPES, R.E. Estudos de transitividade em língua portuguesa: o perfil do gênero cartas de venda. Dissertação de Mestrado. LAEL - PUCSP, 2001.

15. MARCANTÔNIO, A. T., SANTOS, M. M.; LEHFELD, N. A. de S. Elaboração e divulgação do trabalho científico, Atlas, São Paulo, Brasil, 1993.

16. MARSON, L. S. C. Comportamento organizacional: estudo de caso dos secretários executivos do estado do Rio de Janeiro. Dissertação de mestrado - UFF - Departamento de Sistema de Gestão, 2009.

17. MARTIN, J. R. English text: System and Structure. Amsterdam: John Benjamins Publishing Co, 1992.

18. MARTIN, J. R.; MATTHIESSEN, C. M. I. M.; PAINTER, C. Working with functional grammar. London: Arnold, 1997. 
19. MOTTA-ROTH, D. Escritura, gêneros acadêmicos e construção do conhecimento. Letras. UFSM, 1998.

20. Escrevendo no contexto: contribuições da Linguística Sistêmico-Funcional para o ensino de redação acadêmica. Paper presented at the 33rd International Systemic Functional Congress. PUC-SP, 2006.

21.

Redação Acadêmica: princípios básicos.1. ed. Santa Maria: Imprensa Universitária, 2001.

22. PAIM, A. S. Aparência física, estereótipos e inserção profissional: um estudo sobre a profissão de secretário executivo segundo a percepção das estudantes de secretariado. Dissertação de Mestrado - UFBA - Departamento de Psicologia, 2007.

23. SCOTT, M.R. WordSmith tools. Oxford: Oxford University Press, 2009.

24. SHERGUE, O. Dimensão da variação no discurso médico acadêmico: o artigo de pesquisa a apresentação de trabalhos científicos em congressos. Dissertação de Mestrado. PUC-SP, 2003.

25. SWALES, J. M. Language and scientific communication: The case of the reprint request. Scientometrics vol.13, pp. 93-101, 1989.

26. Genre analysis - English in academic and research settings. Cambridge University Press, 1990.

27. SWALES, J. M. \& FEAK, C. B. Academic writing for graduate students. Michigan: The University of Michigan Press., 1999.

28. THOMPSON, G. Introducing Functional Grammar. England, Ed. Arnold, 1996.

29. VILAS BOAS, M C. O ensino com pesquisa como metodologia da prática pedagógica: um estudo realizado no curso de Secretariado Executivo da PUCPR. Dissertação de Mestrado PUCPR - Departamento de Educação, 1999. 